\title{
Solar Farming with Agricultural land
}

\section{Khyati Vyas*}

International Solar Business, Fourth Partner Energy Private Limited, India

*Corresponding Author: Khyati Vyas, International Solar Business, Fourth Partner Energy Private Limited, India.

Received: July 10, 2019; Published: September 06, 2019

DOI: 10.31080/ASAG.2019.03.0640

\begin{abstract}
Agriculture is the major resource of each country. The agricultural sector provides a living for most of the population. However, the agricultural sector desires correct irrigation facilities and alternative amenities to reap correct advantages. Another issue during this sector is said to the plight of farmers. Since several crops are seasonal, most of the farmers are not getting a regular supply of financial gain. Farmers don't seem to be having the ability to earn something from their dry/uncultivated land. Alternative energy may be placed to smart used to handle these vital problems with the world.

Solar development is occurring on an enormous scale as lands are being born-again from agricultural land or unused land into solar projects, that represents a tremendous chance to boost our agriculture and improve our food security whereas developing energy at an equivalent time. In places wherever agricultural land is tight and electricity costs high, the economics would possibly play go in favor of dual-use farms. However, at most of the places, farmland remains comparatively plentiful and acres of canopies are unlikely to be possible unless energy and agricultural markets modify.

Keywords: Solar Farming; Agricultural Land Use; Solar-Powered Polyhouse or Greenhouse; Farmers; Duel use of Farmlands; RTPV; Solar; Electrical Phenomenon
\end{abstract}

\section{Abbreviations}

RTPV: Rooftop Solar Photovoltaic; Al: Aluminum.

Agricultural land utilization for solar power plants

There are comparatively few studies on micro climate effects beneath solar modules, however current analysis results show there's very little to no average impact. Air temperatures tend to be cooler beneath the panels throughout the day and hotter beneath the panels at the hour of darkness. One study found that air temperature, humidity, and crop temperature beneath modules was like conditions of full sun. This study found that soil temperatures at night under the modules was lower than that of soil temperatures fully sun all day. There are no studies linking solar development with tormentor issues, however, studies have shown how native plants will thrive underneath solar installations. Some encouraging projects across Massachusetts, Arizona, Germany, China, Croatia, Italy, Japan, and France for a combination of crops with solar panels are known as dual use farms as they provide agricultural and electrical production both at a time. "So far, the pilots are extraordinarily productive in showing that you will simply grow crops and generate electricity at an equivalent time (Figure 1).

The researchers have planted wheat, potatoes, celeriac and herbaceous plant grass within the open and beneath the panels and compared the yields. Solar shading remittent production by $5 \%$ to $19 \%$. However, electricity from the panels, that capture each indirect and direct light-weight, accustomed to power a crop process plant and electrical farm machinery, compensate those prices and increasing land use potency by $60 \%$. 


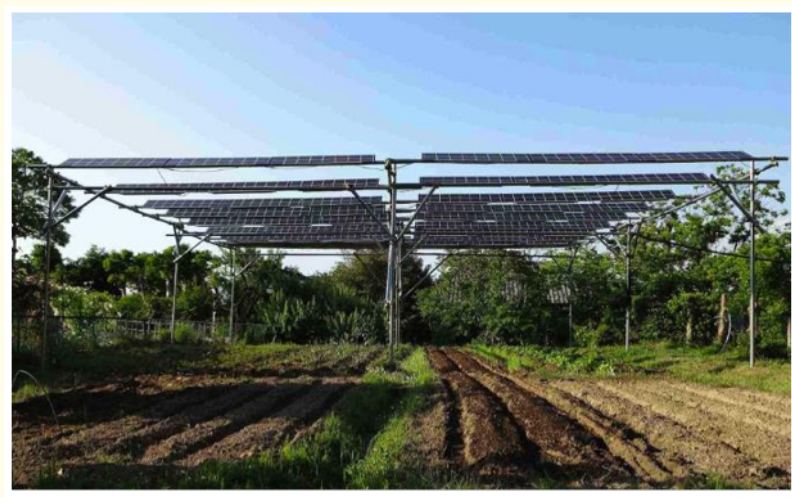

Figure 1: Solar plant with elevated structure over farm land. Source: https://www.renewableenergyworld.com

Solar modules need the utilization of alternative electrical instruments, like inverters and association boxes, that emit some noise. The frequency of the most inverters is 50-60 Hertz, an equivalent as AC electricity in your home or industrial building that is at intervals the very sonic to humans and well below the upper frequencies will not repel animals. Sound is mostly not audible at the sting of the enclosed boundary, The sound is analogous in volume to background noises and dissipates up to 150 feet from the sting of the boundary. Solar installations will support native vegetation and insect surroundings species. Low- height plants will thrive underneath star panels, avoiding the necessity for mowing and keeping the panels open to sky. Insect surroundings will profit native farms and might additionally host agricultural operations.

There are more alternative benefits to the panels in addition. The skin temperature of individuals beneath the panels remains twenty-five degrees cooler than those who are exposed to the sun.

Weed killer is presently sprayed around some star modules to forestall weed growth. Agrochemicals shouldn't give any difficulty. Care needs to be taken not to spray modules themselves, however, if it happens the modules may be washed off with water as they're made from glass and steel or $\mathrm{Al}$ and are designed to face up to outdoor conditions.

Solar will offer many advantages to agricultural land managers to offset the capital prices of putting in solar plants:
- Solar may be put in with zero direct cost of capital through leasing.

- $\quad$ Solar may be put in on marginal agriculture lands and supply a distinct supply of revenue for the farm. This completely different revenue stream will offset the operational expenses of the farm and supply economic resiliency in poor growing years.

- The solar plant need not be installed in current or projected growing areas.

- Co-location of solar and crops installations may be designed to optimize for each electricity and food production.

- The shade beneath the solar modules will provide planting high-value, shade- tolerant, and hand-harvested crops which will not commonly be out there in markets (i.e. lettuces in desert areas, etc.).

Poly-house or green-house mounted star plant

A Polyhouse or greenhouse is an indoor house wherever a range of plants are grown perennially in a controlled temperature, humidity, air flow, and lighting conditions. Green- house or Polyhouse is an established technology in Asian nation, and plenty of alternative countries; enterprising farmers have according fivefold increase in agricultural yield and resultant revenue per acre of land. Central and state governments additionally encouraging this concept of farming by providing $40-60 \%$ of capital subsidies on investments created by farmers. Innovative irrigation ways, like drip or mist, have reduced the water demand in poly homes by over 60 $\%$ per acre for typical crops. One acre of poly-house additionally creates $10-12$ jobs.

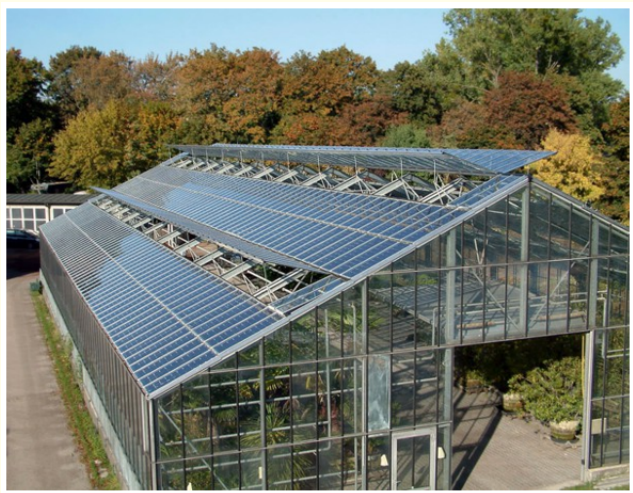

Figure 2: Solar Panel on Greenhouse. Source: http://bmrcnews.com 
Polyhouse or greenhouse with RTPV is very positively enforced in developed countries with colder climates; PV panels are integrated into the rooftop of these structures. This design permits heat to keep at bay within the green house, that contributes to create the inner conditions favorable for plant growth. However, within the tropical regions, the standard roof of poly house is intended as a broken dome structure that permits higher air circulation and ventilation and therefore controls the ambient temperature. Poly house with RTPV needs to be constructed with stronger design consideration to accommodate the additional weight of the panels and their mounting structures.

Agricultural specialists claim that whereas it's technically possible to apply PV panels on Polyhouse rooftop but, it'll hinder lightweight from coming into the structure, and negatively impact plant growth. However, the artificial lighting within the Polyhouse can catch up on the loss of natural lightning.

$1 \mathrm{MW}$ of the solar plant on Polyhouse can be constructed on around seven Acres of land, which will have 12\% auxiliary power consumption for operational purpose. The land requirement will be same whereas, electricity exported to the grid will be more, as a result farmer will have benefit on revenues and yield both. PV system developers worry that Cost of construction will be higher for RTPV Systems on polyhouse structure. However, with correct structural engineering, the prices would possibly return down by reducing the dimensions of the mounting structures and accurate designs.

Other advantages of solar energy on farmlands

In addition, solar power can also be utilized to run irrigation system. Solar power will offset the electricity needed for pumping, and supply power to remote irrigation systems, where grid power is not available. Solar irrigation pumps are presently operational in many regions of Africa, South America, and India [1-6].

\section{Conclusion}

This projected innovation of polyhouses or greenhouses with RTPV and solar farms with agricultural land has the potential to create the methods for comprehensive growth by linking solar power with agriculture. However, reckoning on the present land use of the leaseholder, installation of Solar plant may vary on the location. If current farming operations are favorable for solar pow- er generation or unused land exists, the idea of dual use of land can be still allowed. This might even culminate into a particular policy being declared to push this idea.

\section{Bibliography}

1. T Harinarayana and K Sri Venkata Vasavi. "Solar Energy Generation Using Agriculture Cultivated Lands". Smart Grid and Renewable Energy 5 (2014): 31-42.

2. Beena Patel., et al. "Agro-electric Model"- A sustainable solar plant with dual use of land and water for energy and food security, Cumulus Mumbai 2015: In a planet of our own - a vision of sustainability with focus on water.

3. Dupraz Christian., et al. "Combining solar photovoltaic panels and food crops for optimizing land use: Towards new agrivoltaic schemes". Renewable Energy 36 (2011): 2725-2732.

4. http://bmrcnews.com/dye-sensitized-solar-cells-dssc-market-2019-size-applicationrevenue-types-trends-in-futurescope-to-2025/

5. https://www.renewableenergyworld.com/arti cles/2013/10/japan-next-generation-farmers-cultivate-agriculture-and-solar-energy.html

6. https://ensia.com/features/solar-farms/

\section{Volume 3 Issue 10 October 2019}

(c) All rights are reserved by Khyati Vyas. 